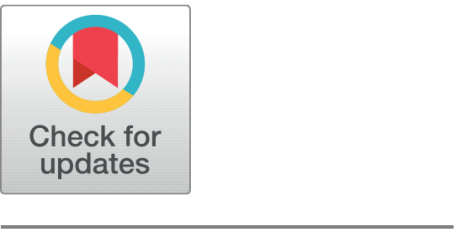

G OPEN ACCESS

Received: $31-03-2020$

Accepted: 23-04-2020

Published: 07-05-2020

Editor: Dr. Natarajan Gajendran

Citation: Jasmine P, Robin PSV (2020) Water quality index of Aedes aegypti (L) breeding sites in southern coastal areas of India. Indian Journal of Science and Technology 13(12): 1310-1315. https://doi.org/ 10.17485/IJST/V13i12.87

*Corresponding author. P Jasmine

PhD Scholar, Department of Zoology and Research Centre, Scott Christian College (Affiliated to Manonmaniam Sundaranar University), Nagercoil, 620 003, Tamil Nadu, India jasminejas061@gmail.com

Funding: None

Competing Interests: None

Copyright: @ 2020 Jasmine, Robin. This is an open access article distributed under the terms of the Creative Commons Attribution License, which permits unrestricted use, distribution, and reproduction in any medium, provided the original author and source are credited.

Published By Indian Society for Education and Environment (iSee)

\section{Water quality index of Aedes aegypti (L) breeding sites in southern coastal areas of India}

\author{
P Jasmine $^{1 *}$, Perinba Smith V Robin ${ }^{2}$ \\ 1 PhD Scholar, Department of Zoology and Research Centre, Scott Christian College \\ (Affiliated to Manonmaniam Sundaranar University), Nagercoil, 620 003, Tamil Nadu, India \\ 2 Head and Associate Professor, Department of Zoology and Research Centre, Scott Christian \\ College (Affiliated to Manonmaniam Sundaranar University), Nagercoil, 620 003, Tamil Nadu, \\ India
}

\section{Abstract}

Background/Objectives: Breeding habitat can influence the biological features of the mosquitoes and can be utilized to improve the implementation of the vector control. The major objective of this study was to evaluate the Water Quality Index of various breeding sites. Methods/Statistical analysis: Community Development Blocks $(n=9)$ of the Kanyakumari district were selected as the main research site to study the water quality characteristics of Ae. aegypti mosquitoes' breeding sites. The physicochemical parameters in the mosquito breeding containers were analyzed. Findings: Sixteen types of breeding sites were analyzed, among them nine breeding sites had good quality of water and remaining seven breeding sites contained slightly polluted water. Novelty/Applications: The awareness of water quality parameters of mosquito breeding sites can be used in the adoption of preventive methods.

Keywords: Community development blocks; Physico-chemical parameters; Aedes aegypti; Breeding sites

\section{Introduction}

Aedes aegypti mosquitoes are competent vectors of several pathogens of human health importance such as chikungunya, dengue, yellow fever, and Zika viruses that causes dangerous diseases like dengue, yellow fever, and chikungunya ${ }^{(1)}$. Among them, dengue fever has become an important public health problem as the number of reported cases continues to increase, especially with more severe forms of the disease such as dengue haemorrhagic fever, dengue shock syndrome and unusual symptoms in central nervous system $^{(2)}$.

The selection of suitable breeding sites to lay eggs is basic to the distribution and establishment of Ae. aegypti population. The activities like reproduction, aggregation and offspring production are controlled by chemical methods. They are attracted towards the odour depending on the nature of the stimulus. Females use their olfactory sense to select a place with the nutrients necessary for the development of the larvae. This factor is essential, not just to enhance the chances of survival, also in guaranteeing 
the emergence of many Ae. aegypti adults ${ }^{(3)}$. Ae. aegypti may prefer containers as a favorable breeding source because of conducive water quality characteristics. These mosquitoes primarily breed in artificial water containers and its life cycles are closely related to human activities. The abundance of mosquitoes has a negative effect on the quality of life of humans and their environment ${ }^{(4)}$. In urban areas, mosquitoes are prone to utilize water-filled containers in the development of immature life stages. Most of the mosquito species prefer to ovipositor in shaded areas ${ }^{(5)}$. Water conditions, location, presence of larval nutrient and shade are the factors in the selection of breeding sites ${ }^{(4)}$. Study on the dengue vector distribution along with the water quality can provide an insight to the complexity of the dengue outbreak.

The types of containers, physicochemical parameters of water, and conditions of water containers are essential for the breeding of Ae. aegypti. Embryonic development of mosquitoes is influenced by water temperature. Ae. aegypti can tolerate both acidic and basic conditions of water. The mechanisms used to regulate body $\mathrm{pH}$ in acidic and alkaline conditions are not mutually exclusive, maybe physically by acid-base secreting intercalated cells of the mammalian nephron. Aquatic insects fully depend on epithelial transport across renal systems for acid-base homeostasis. Most of the studies revealed that a tough relationship exists between the water acidity and the composition of the macro invertebrate community ${ }^{(6)}$.

The physicochemical analysis of water is the most important aspect to determine the quality of lotic water for its best uses, certain water quality indicators must be monitored and controlled. In physicochemical parameters, temperature controls the rate of metabolic and reproductive activities of aquatic organisms. $\mathrm{P}^{\mathrm{H}}$ is an indicator of the acidic or alkaline condition of the water. The aquatic life tends to be very sensitive towards $\mathrm{P}^{\mathrm{H}}$. The measure of water capacity to convey an electric current is the electrical conductivity. It brings to the measurement of total dissolved solids in water. Total dissolved solids (TDS) indicate the number of ions present in the water and an analysis of the quality of water. High TDS in water reduces clarity in water and decreases photosynthesis in aquatic plants. Dissolved oxygen indicates the ability of water to support aquatic life. Biological oxygen demand measures the amount of food for bacteria in water. Total hardness mainly depends on the calcium and magnesium salts. The increase of nitrate, calcium, and magnesium causes eutrophication which affects the water quality.

Water quality index (WQI) helps to calculate a large amount of data into simple terms such as excellent, good and bad. Based on many water quality parameters, a water quality index provides a single number that expresses the overall water quality at a certain location and time. WQI can be used as a tool in comparing the water quality of different sources and a general idea of the possible problems with water in a particular location. These indices are among the most effective ways to communicate the information on water quality trends for quality management ${ }^{(7)}$.

WQI can assist in the establishment of priorities by providing numerical data on overall water quality in regular water samples instead of evaluating the breeding site in specific water quality parameters ${ }^{(8)}$. It provides overall idea about the nature of aquatic habitats of Ae. Aegypti, this includes Biological Oxygen Demand (BOD), Chemical Oxygen Demand (COD), Electrical Conductivity (EC), pH, Dissolved Oxygen (DO, Total Dissolve Solids (TDS), Total Hardness, Nitrate, Chloride, Calcium and Magnesium presence in the water in a single and understandable number. The method to identify, label and classify organisms is largely built around morphological characteristics. Therefore, the present study investigated and identified Ae. aegypti mosquitoes' breeding performance in natural and artificial water containers that serve in the potential dengue fever (DF) transmission in Kanyakumari district. The results would enable to provide awareness about Ae. aegypti mosquitoes' aquatic habitats and preventive measures necessary.

\section{Materials and methods}

\subsection{Study Area}

Community Development Blocks ( $n=9$ ) of the Kanyakumari district were selected as the main research sites to study the water quality characteristics of Ae. aegypti mosquitoes' breeding sites. The selected landscape characteristics of this area include the developing urban areas and rural areas. The major land-use in this area is residential and commercial. The map in Figure 1 shows the locations of the study area included for the study.

\subsection{Mosquito Sampling}

The selection of the localities was based on the constant occurrence of dengue fever cases for two years (2017-2019). The waterholding containers were visually inspected for the presence of water with Ae. aegypti immature mosquitoes such as larvae and pupae. All the water-holding containers detected during the survey were counted and classified into 16 categories based on the breeding site identity (BSID). The factors for the categories of BSID were based on observed at the sampling sites were, they are BS1: Plastic tubs; BS2: Flower vases; BS3: Buckets; BS 4: Drums; BS5: Earthen pots; BS6: Vehicle Tires; BS7: Coconut shells; BS8: Plastic sheets; BS9: Glass materials; BS10: Water Reservoirs; BS11: Discarded shoes; BS12: Dust carriers; BS13: Ant guards; 


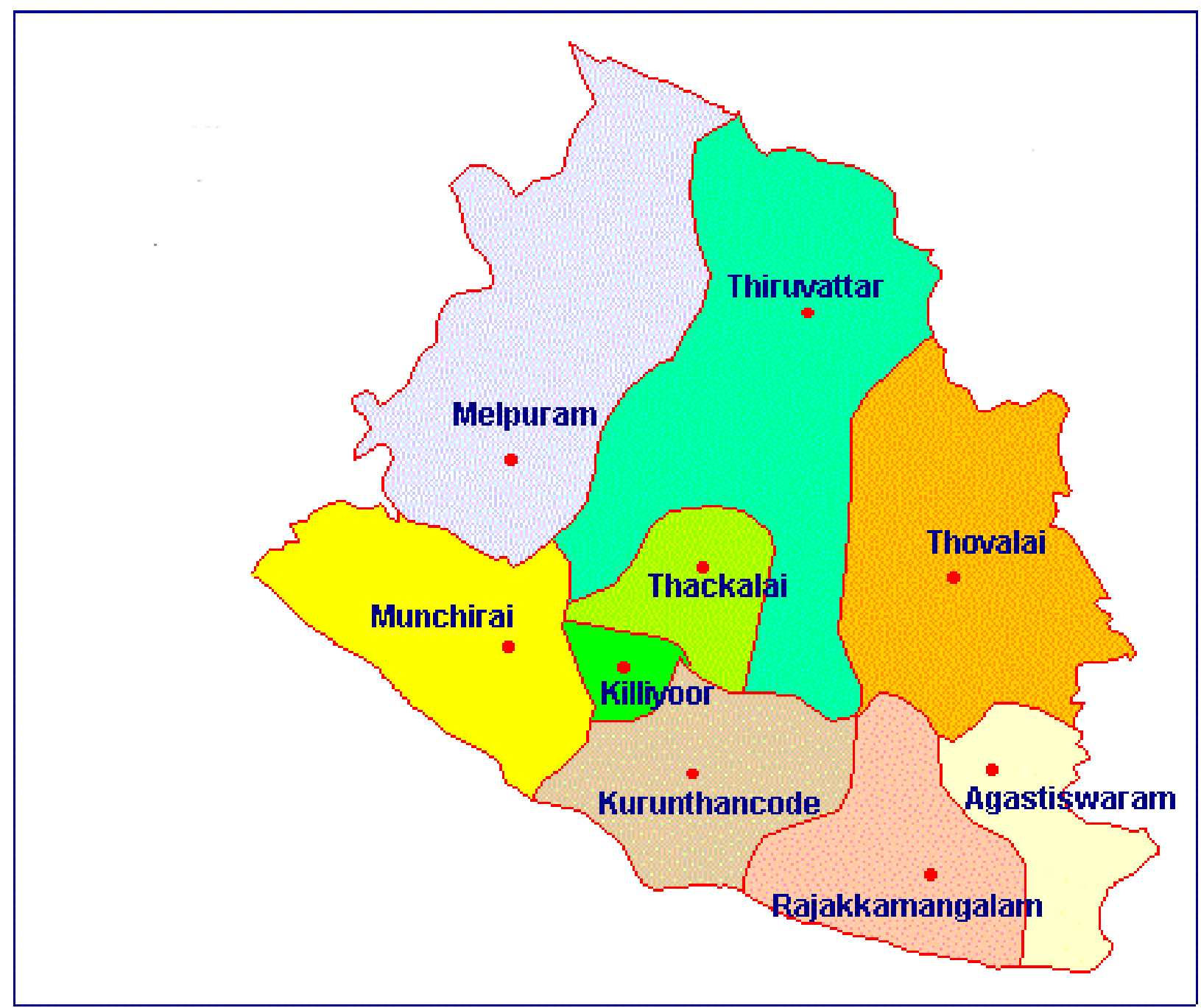

Fig 1. Map showing the location of the study area

BS14: pile of metals; BS15: Waste water from refrigerators and BS16: Tree holes and leaves.

\subsection{Measurement of Water Quality Parameters}

Eleven parameters were considered to assess the water quality characteristics of Ae. aegypti breeding sites, which included physicochemical parameters. A physical analysis of water in the breeding habitat was performed in-situ. Temperature $\left({ }^{\circ} \mathrm{C}\right)$ of water before sampling, were tested on-site at the time of collection with the help of a thermometer. The physicochemical parameters like Electrical Conductivity, $\mathrm{pH}$, Calcium, and Magnesium were analyzed according to standard methods prescribed by the Government of India ${ }^{(9)}$. Dissolved Oxygen, Biological Oxygen Demand, Chemical Qxygen Demand, Total Dissolved Solids, Total Hardness, Nitrate, and Chloride were analyzed according to standard methods as per American Society for Testing and Materials International ${ }^{(10)}$.

\subsection{Calculation of the Water Quality Index (WQI)}

The calculation of the WQI was done using a weighted arithmetic water quality index, which was suggested by Brown et al. ${ }^{(11)}$. Weighted arithmetic water quality index (WQI) was calculated by using the following equation,

$$
\mathrm{WQI}=\Sigma \mathrm{N} 1 \mathrm{R} 1 / \Sigma \mathrm{N} 1
$$


Where,

$\mathrm{R}_{1}=$ Quality rating for the nth water quality parameter,

$\mathrm{N}_{1}=$ Unit weight for nth water quality parameter.

The unit weight $\left(\mathrm{N}_{1}\right)$ of the various water quality parameters is inversely proportional to the recommended standards for the corresponding parameters. The value of $\mathrm{R}_{1}$ is calculated using the following equation:

$$
\mathrm{R}_{1}=100(\mathrm{OV} \mathrm{n}-\mathrm{OV} 10) /(\mathrm{OSn}-\mathrm{OV} 10)
$$

Where,

$\mathrm{R}_{1}=$ Quality rating for the $\mathrm{n}^{\text {th }}$ water quality parameter,

$\mathrm{O}_{V} \mathrm{n}=$ Estimated value of the $\mathrm{n}^{\text {th }}$ water quality parameters of the collected sample,

$\mathrm{O}_{S} \mathrm{n}=$ Standared permissible value of the $\mathrm{n}^{\text {th }}$ water quality parameter,

$\mathrm{O}_{V} 10=$ Ideal value of the $\mathrm{n}^{\text {th }}$ water quality parameter in pure water.

(i.e. 0 for all other parameters except the parameter for $\mathrm{PH}$ and $\mathrm{DO}$ ( 7 and $14.6 \mathrm{mg} / \mathrm{l}$ respectively). For $\mathrm{pH}$, the ideal value is 7.0 (for natural/pure water) and a permissible value is 8.5 (for polluted water). Therefore, the quality rating for $\mathrm{pH}$ was calculated from the following equation:

$$
\mathrm{R}_{\mathrm{pH}}=100(\mathrm{OV} \mathrm{pH}-7.0) /(8.5-7.0)
$$

Where,

$\mathrm{O}_{V} \mathrm{pH}=$ observed value of $\mathrm{pH}$.

For dissolved oxygen, the ideal value is $14.6 \mathrm{mg} / \mathrm{l}$ and the standard permissible value for drinking water is $5 \mathrm{mg} / \mathrm{l}$. Therefore, its quality rating is calculated from the following equation:

$$
\mathrm{RDO}=100(\mathrm{OV} \mathrm{DO}-14.6) /(5.0-14.6)
$$

Where,

$\mathrm{O}_{V} \mathrm{DO}=$ observed value of dissolved oxygen.

The unit weight $(\mathrm{Wn})$ for each water quality parameter is calculated by the following formula

$$
\mathrm{N} 1=\mathrm{K} / \mathrm{OSn}
$$

Where,

$\mathrm{K}=$ proportionality constant

Table 1. Water quality index level with water quality status

\begin{tabular}{lll}
\hline Sl. No. & water quality index level & water quality status \\
\hline 1 & $0-25$ & Excellent \\
2 & $26-50$ & Good \\
3 & $51-75$ & Poor \\
4 & $76-100$ & Very poor \\
5 & Above 100 & contaminated water \\
\hline
\end{tabular}

\section{Results and Discussion}

Sixteen types of breeding sites were analyzed, among them nine breeding sites had good quality of water and remaining seven breeding sites contained slightly polluted water. The water had become polluted due to the storage of the water in the container for long period with ambient relative humidity and temperature, which favor the mosquitoes to breed. The results found here implies that Ae. aegypti can thrive in a variety of habitat with clear, turbid or polluted, which are used for drinking or washing. Ae. aegypti more commonly prefer outside areas such as open spaces with shaded vegetation, car tyres, plastic sheets and coconut shells.

In the present study the calculated water quality index of BS1, BS2, BS3, BS4, BS5, BS6, BS7, BS8, BS9, BS10, BS11, BS12, BS13, BS14, BS15 and BS16 were 46.15, 48.74, 50.50, 52.19, 45.113, 46.053, 50.877, 50.448, 40.133, 52.711, 50.225, 48.199, 54.184, $47.408,43.385$ and 49.058 respectively. The physico-chemical parameters in the mosquito breeding containers were found to be 
ranging from, $38.41 \pm 0.05$ to $50.6 \pm 0.02,7.2 \pm 0.01$ to $7.8 \pm 0.1,4.67 \pm 0.01$ to $8.5 \pm 0.07,3.42 \pm 0.2$ to $5.23 \pm 0.05,35.2 \pm$ 0.07 to $58.6 \pm 0.01,4.9 \pm 0.05$ to $8.23 \pm 0.05,0.31 \pm 0.1$ to $0.82 \pm 0.07,3.7 \pm 0.01$ to $5.7 \pm 0.1,1.02 \pm 0.01$ to $1.49 \pm 0.07$ and $0.72 \pm 0.05$ to $1.07 \pm 0.2$ for Conductivity, $\mathrm{pH}, \mathrm{DO}(\mathrm{mg} / \mathrm{L}), \mathrm{BOD}(\mathrm{mg} / \mathrm{L}), \mathrm{TDS}(\mathrm{mg} / \mathrm{L})$, Total Hardness $(\mathrm{mg} / \mathrm{L}), \mathrm{Nitrate}(\mathrm{mg} / \mathrm{L})$, Calcium $(\mathrm{mg} / \mathrm{L})$, Magnesium $(\mathrm{mg} / \mathrm{L})$ and Chloride $(\mathrm{mg} / \mathrm{L})$ respectively ( Table 2$)$.

Table 2. Water Quality Index (WQI) in Ae. aegypti Breeding Sites

\begin{tabular}{llll}
\hline S1. No. & BSID & Types of breeding sites & WQI $=\sum \mathbf{W n Q n} / \sum \mathbf{W n}$ \\
\hline 1 & BS1 & Plastic tubs & 46.152 \\
2 & BS2 & Flower vases & 48.741 \\
3 & BS3 & Buckets & 50.504 \\
4 & BS4 & Drums & 52.190 \\
5 & BS5 & Earthen pots & 45.113 \\
6 & BS6 & Vehicle tyres & 46.053 \\
7 & BS7 & Coconut shells & 50.877 \\
8 & BS8 & Plastic sheets & 50.448 \\
9 & BS9 & Glass materials & 40.133 \\
10 & BS10 & Water Reservoirs & 52.711 \\
11 & BS11 & Discarded shoes & 50.225 \\
12 & BS12 & Dust carriers & 48.199 \\
13 & BS13 & Ant guards & 54.184 \\
14 & BS14 & Group of metals & 47.408 \\
15 & BS15 & Waste water from refrigerators & 43.385 \\
16 & BS16 & Tree holes and leaves & 49.058 \\
\hline
\end{tabular}

The results of the present study correlates with the study of Tiimub et al. ${ }^{(12)}$ reported that the levels of physico-chemical parameters in the mosquito breeding waters which were found to be ranging from $17.03 \pm 0.18^{\circ} \mathrm{C}-24.06 \pm 0.18^{\circ} \mathrm{C}, 17.03 \pm$ $4.04 \mathrm{mg} / \mathrm{L}-96.67 \pm 4.04 \mathrm{mg} / \mathrm{L}, 1.09 \pm 3.23 \mathrm{mg} / \mathrm{L}-35.67 \pm 3.23 \mathrm{mg} / \mathrm{L}, 3.97 \pm 0.13 \mathrm{mg} / \mathrm{L}-7.43 \pm 0.13 \mathrm{mg} / \mathrm{L}, 17.00 \pm 1.30-83.00$ \pm 1.30 and $7.77 \pm 0.0-10.70 \pm 0.01$ for Temperature, TSS, TDS, DO, EC and pH respectively.

The graph in the Figure 2 shows the Water Quality Index of various breeding sites with Ae. aegypti The results were relatively much lower when compared to their corresponding EPA Maximum Permissible Limits of $<3^{\circ} \mathrm{C}, 1000 \mathrm{mg} / \mathrm{l}, 50 \mathrm{mg} / \mathrm{l}, 50 \mathrm{mg} / \mathrm{l}$, $1500 \mathrm{mg} / \mathrm{l}$ and 6-9 for water that are likely to be polluted. The mean differences between all the physicochemical parameters were generally statistically significant at approximately $\mathrm{P}<0.005$ between the two control sites. In the rest of the ordinary sampling sites, even though between the two control sites, there were no significant differences observed.

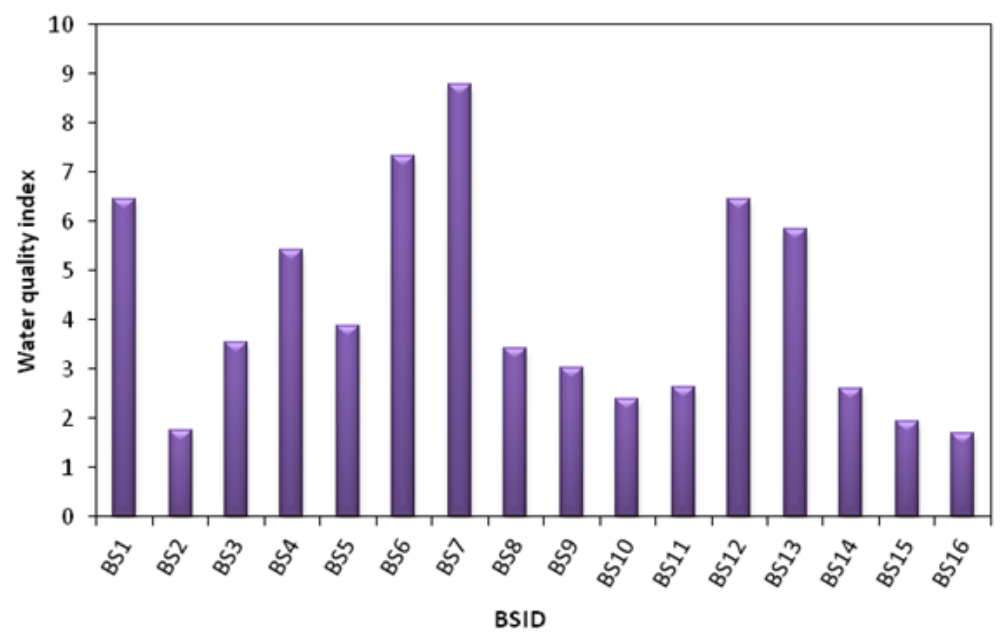

Fig 2. Water Quality Index of various breeding sites with Ae. aegypti 
Temperature and $\mathrm{pH}$ were both associated with an increase or decrease in larval density. In the present study across all breeding sites, water mean $\mathrm{pH}$ ranged from 7.2 to 7.8 and temperature ranged from $25^{\circ} \mathrm{C}$ to $27^{\circ} \mathrm{C}$. Sanford ${ }^{(13)}$ reported that pond water temperature affects both spawning and growth of mosquito larvae and pupae. The mean temperatures of the water sites ranged between $17.03 \pm 0.18^{\circ} \mathrm{C}$ to $24.06 \pm 0.18^{\circ} \mathrm{C}$.

Breeding sites with high $\mathrm{pH}$ range are not ideal for mosquito breeding and survival due to free ammonia, which tends to increase with rising $\mathrm{pH}$. The neutral $\mathrm{pH}$ range from 6.8 to 7.2 was a preferred breeding site by mosquitoes. Therefore, outside this range mosquito eggs, larvae and pupae growth were reduced and at the $\mathrm{pH}$ range below 4.5 or above 10 , mortality occurs. Ae. aegypti have inability to survive and develop in waters with $\mathrm{pH}$ ranging from 4 to 11 . They regulate hemolymph $\mathrm{pH}$ over this $\mathrm{pH}$ range. Even more notable is their ability to tolerate abrupt transfer from one extreme of this $\mathrm{pH}$ range of the other. The results of this study found that the Ae. aegypti mosquitoes prefer to oviposit in slightly alkaline water. Earlier studies reported that Aedes species had an inclination for a narrow $\mathrm{pH}$ range $(6-8)$, while Culex and Armigeres occurred in the broader range of $\mathrm{pH} 6-10^{(14)}$.

Adebote et al. ${ }^{(15)}$ reported that mosquitoes breeding in rock pools on Inselbergs around Zaria, Northern Nigeria determined the $\mathrm{pH}$ level of pools that supported Aedes vittatus breeding to be ranging from 5.97 to 9.85 . From this result, it can be observed that Ae. vittatus has wider $\mathrm{pH}$ level tolerance compared to other mosquito species such as Anopheles ardensis, Anopheles distinctus, Anopheles wilsoni, and Culex ingrami. Filter feeding mosquitoes require fresher, transparent and more oxygenated waters to complete its life cycle. Therefore more suitable Dissolved Oxygen (DO) requirement is essential for the development of Ae. aegypti. Low level DO of aquatic habitat indirectly reduced the TSS and TDS concentrations. Higher concentrations of TSS and TDS may reduce transparency and increase oxygen deficiency. High concentrations of these parameters can be harmful to some species of mosquitoes.

\section{Conclusion}

Ae. aegypti is the vital species found in rubber estates because coconut shells are used to collect rubber milk. Kanyakumari district has lots of rubber plantation areas. Commonly used discarded materials also act as the favorable breeding places of these dengue vectors. The knowledge of water quality parameters of mosquito breeding sites can be used to for the adoption of preventive methods during the pre-monsoon season. It is one of the source reduction activities which are area specific, but can be implicative for control of mosquito borne diseases all over the globe.

\section{References}

1) Clements AN, Harbach RE. Controversies over the scientific name of the principal mosquito vector of yellow fever virus - expediency versus validity. Journal of Vector Ecology. 2018;43(1):1-14. doi:10.1111/jvec.12277.

2) Pancharoen C, Kulwichit W, Tantawichien T, Thisyakorn U, Thisyakorn C. Dengue infection: a global concern. Journal of the Medical Association of Thailand. 2002;85:25-33.

3) Francisco P, Castro JD, Walter FS, Mauricio M, Filho LDL, Almeida RPD, et al. Ciclo de vida de Aedes (Stegomyia) aegypti (Diptera, Culicidae) emaguas com diferentes caracteristicas. Iheringia, Serie Zoologia. 2009;99:281-285.

4) Dom NC, Ahmad AH, Ishak AR, Ismail R. Assessing the Risk of Dengue Fever based on the Epidemiological, Environmental and Entomological Variables. Procedia - Social and Behavioral Sciences. 2013;105:183-194. doi:10.1016/j.sbspro.2013.11.019.

5) Dejene G, Tekie H, Michael TG, Balkew M, Mesfin A. Breeding sites of Aedes aegypti: potential dengue vectors in Dire Dawa. Interdisciplinary Perspectives on Infectious Diseases. 2005;8.

6) Weeraratne TC, Perera MDB, Mansoor MACM, Karunaratne SHPP. Prevalence and breeding habitats of the dengue vectors Aedes aegypti and Aedes albopictus (Diptera: Culicidae) in the semi-urban areas of two different climatic zones in Sri Lanka. International Journal of Tropical Insect Science. 2013;33(04):216-226. doi:10.1017/s174275841300026x.

7) Jagadeeswari PB, Ramesh KP. Water Quality Index for assessment of water quality in south Chennai coastal aquifer. International Journal of Chem Tech Reaearch. 2012;4(4).

8) Young KR, Augustine C, Anderson A. 2009.

9) Standard analytical procedures for water analysis. Hydrology Project. Government of India and Government of the Netherlands. 1999.

10) American Society for Testing and Materials International. E 939-94 (reapproved 2000): standard test method of field testing topical applications of compounds as repellents for medically important and pest arthropods (including insects, ticks, and mites): I. Mosquitoes. 2000.

11) Brown RM, Mcclelland NI, Deininger RA, Connor O, F M. 1972. Available from: https://link.springer.com/chapter/10.1007/978-1-4684-2856-8_15.

12) Tiimub BM, Adu BK, Obiri-Danso K. Physicochemical assessment of mosquito breeding sites from selected mining communities at the Obuasi municipality in Ghana. Journal of Environment and Earth Science. 2012;2(10):2224-3216.

13) Sanford MR, Chan K, Walton WE. Effects of Inorganic Nitrogen Enrichment on Mosquitoes (Diptera: Culicidae) and the Associated Aquatic Community in Constructed Treatment Wetlands. Journal of Medical Entomology. 2005;42(5):766-776. doi:10.1603/0022-2585(2005)042[0766:eoineo]2.0.co;2.

14) Lalithanjalie A, D, Dilani D, R. Vector mosquito diversity and habitat variation in a semi urbanized area of Kelaniya in Srilanka. International Journal of Entomological Research. 2014;2(01):15-21.

15) Adebote DA, Oniye SJ, Muhammed YA. Studies on mosquitoes breeding in rock pools on inselbergs around Zaria, northern Nigeria. J Vector Borne Dis. 2008;45(1):21-28. 